Supporting Information

\title{
Solution-Mediated Annealing Pathways are Critical for Supramolecular Ordering of Complex Macrocycles at Surfaces
}

Henry D. Castilloł, Jing Yangt, Sibali Debnath, James R. Dobscha, Colleen Q. Trainor, Riley D. Mortensen, Krishnan Raghavachari, Amar H. Flood, Peter J. Ortoleva, and Steven L. Tait*

Molecular Materials Design Laboratory, Department of Chemistry, Indiana University, 800 E. Kirkwood Avenue, Bloomington, IN 47405, United States

\$These authors contributed equally to this work.

Email of corresponding author: tait@indiana.edu

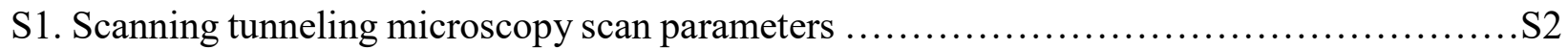

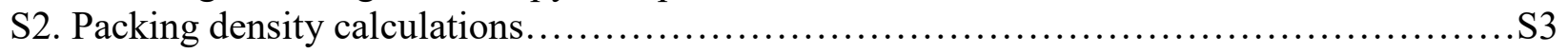

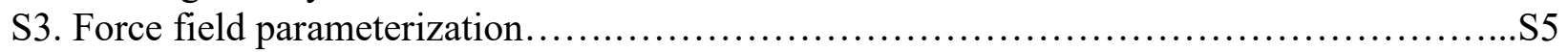

S4. Additional information on the design and conditions of molecular dynamics simulations.....S7

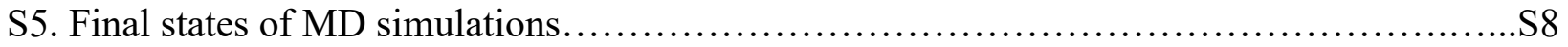

S6. Self-assembly of tricarb-10-10-10 and tricarb-6-6-6................................... 10

S7. Variable temperature self-assembly of tricarb-6-6-18 and tricarb-6-10-Cy.............S11

S8. Variable solvent self-assembly of tricarb-6-6-18 and tricarb-6-10-Cy.................S13

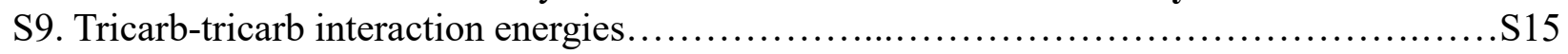

S10. Honeycomb deterioration facilitated by TCB insertion............................... 17

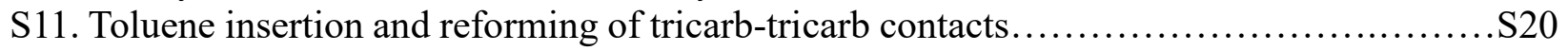

S12. Honeycomb to disordered progression of tricarb-1-1-1 ............................S22

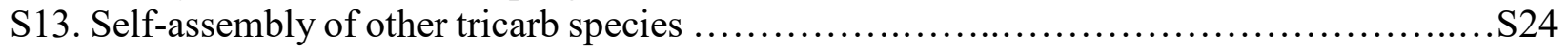

S14. Ordered domain size as a function of solvent, temperature, and peripheral groups ........S25

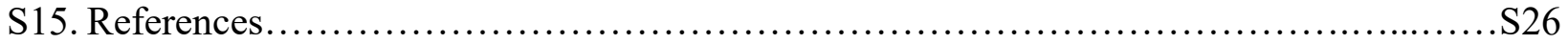




\section{S1. Scanning tunneling microscopy scan parameters}

Table S1. Specific scanning conditions for STM images in the main text.

\begin{tabular}{|c|c|c|c|c|c|c|c|c|c|}
\cline { 2 - 10 } \multicolumn{1}{c|}{} & \multicolumn{3}{c|}{ Figure 1 } & \multicolumn{3}{c|}{ Figure 2 } & \multicolumn{3}{c|}{ Figure 3 } \\
\cline { 2 - 10 } \multicolumn{1}{c|}{} & a & b & c & a & b & c & a & b & c \\
\hline$V_{\text {sample }}(\mathrm{V})$ & -0.6 & -0.5 & -0.7 & -0.7 & -0.4 & -0.8 & -0.7 & -0.4 & -0.7 \\
\hline$I_{t}(\mathrm{nA})$ & 1.10 & 0.60 & 0.15 & 0.80 & 0.15 & 1.70 & 1.30 & 0.15 & 0.90 \\
\hline
\end{tabular}




\section{S2. Packing density calculations}

The 2D packing density of the ordered honeycomb structure, $\sigma_{\text {honeycomb, was directly }}$ calculated from the unit cell and also by counting tricarb molecules within a given area $(N=4$ different images). Both methods resulted in the same value ( $\sigma_{\text {honeycomb, unit cell }}=0.28 \pm 0.01$ tricarb $/ \mathrm{nm}^{2}$; $\sigma_{\text {honeycomb, counting }}=0.28 \pm 0.02$ tricarb $/ \mathrm{nm}^{2}$ ), which is consistent with measurements in our prior study. ${ }^{1}$ Flood mapping was also attempted to determine $\sigma_{\text {honeycomb }}$, but results were unreliable; $\sigma$ varied with the flooding parameters and ranged from 0.27 to 0.31 tricarb $/ \mathrm{nm}^{2}$.

Since the disordered structure lacks long-range order (no regular unit cell), $\sigma_{\text {disordered }}$ was calculated by counting tricarb molecules within a given STM scan area. The disordered structures show some local variation in packing: some areas are more porous and others are more tightly packed (Table S3). If packing density analysis is done on very small local areas (5 $\mathrm{nm} \times 5 \mathrm{~nm})$, local variations in packing density can be obtained, in extreme cases, of $0.20-0.24$ tricarb $/ \mathrm{nm}^{2}$ for porous regions and $0.40-0.52$ tricarb $/ \mathrm{nm}^{2}$ for tightly packed regions. To obtain a representative value of the packing density, $\sigma_{\text {disordered }}$, tricarb molecules were counted over areas that were large enough to have a representative population of all types of disordered packing (Table S2). Ten STM images of tricarb-6-10-Cy at $300 \mu \mathrm{M}$ on HOPG in a range of scan sizes (between $15 \mathrm{~nm} \times 15 \mathrm{~nm}$ and $50 \mathrm{~nm} \times 50 \mathrm{~nm}$ ) were analyzed to obtain $\sigma_{\text {disordered }}=0.34 \pm 0.03$ tricarb $/ \mathrm{nm}^{2}$. Eleven additional STM images (between $10 \mathrm{~nm} \times 10 \mathrm{~nm}$ and $50 \mathrm{~nm} \times 50 \mathrm{~nm}$ ) of disordered structures of either tricarb-6-6-6, tricarb-6-10-Cy, or tricarb-6-6-18 at concentrations between $10 \mu \mathrm{M}$ and $1000 \mu \mathrm{M}$ were analyzed individually and found to match this value of $\sigma_{\text {disordered }}$ (Table S3), verifying that it is consistent across that range of tricarb species and concentrations when large areas $(\geq 10 \mathrm{~nm} \mathrm{x}$ $10 \mathrm{~nm}$ ) are analyzed.

Table S2. $\sigma_{\text {disordered }}$ obtained from ten images of disordered structures of tricarb-6-10-Cy at 300 $\mu \mathrm{M} . \sigma$ was calculated by counting the number of tricarb molecules within a scanned area. $N=2330$ molecules.

\begin{tabular}{|c|c|c|c|}
\hline Image & $\begin{array}{c}\text { Number of } \\
\text { tricarb } \\
\text { molecules }\end{array}$ & $\begin{array}{c}\text { Scan area } \\
\left(\mathrm{nm}^{2}\right)\end{array}$ & $\begin{array}{c}\sigma_{\text {disordered }} \\
\text { (tricarb/nm }\end{array}$ \\
\hline 1 & 154 & 400 & 0.39 \\
\hline 2 & 136 & 400 & 0.34 \\
\hline 3 & 151 & 400 & 0.38 \\
\hline 4 & 125 & 400 & 0.31 \\
\hline 5 & 874 & 2500 & 0.35 \\
\hline 6 & 235 & 625 & 0.38 \\
\hline 7 & 264 & 900 & 0.29 \\
\hline 8 & 134 & 400 & 0.34 \\
\hline 9 & 176 & 625 & 0.28 \\
\hline 10 & 81 & 225 & 0.36 \\
\hline SUM & $\mathbf{2 3 3 0}$ & $\mathbf{6 8 7 5}$ & $\mathbf{0 . 3 4}$ \\
\hline & & stdev & 0.03 \\
\hline
\end{tabular}


Table S3. STM images of disordered structures for several tricarb species and concentrations (as indicated). 2D packing density, $\sigma_{\text {disordered }}$, is calculated individually for each image and found to be consistent with the value tabulated in Table S1.

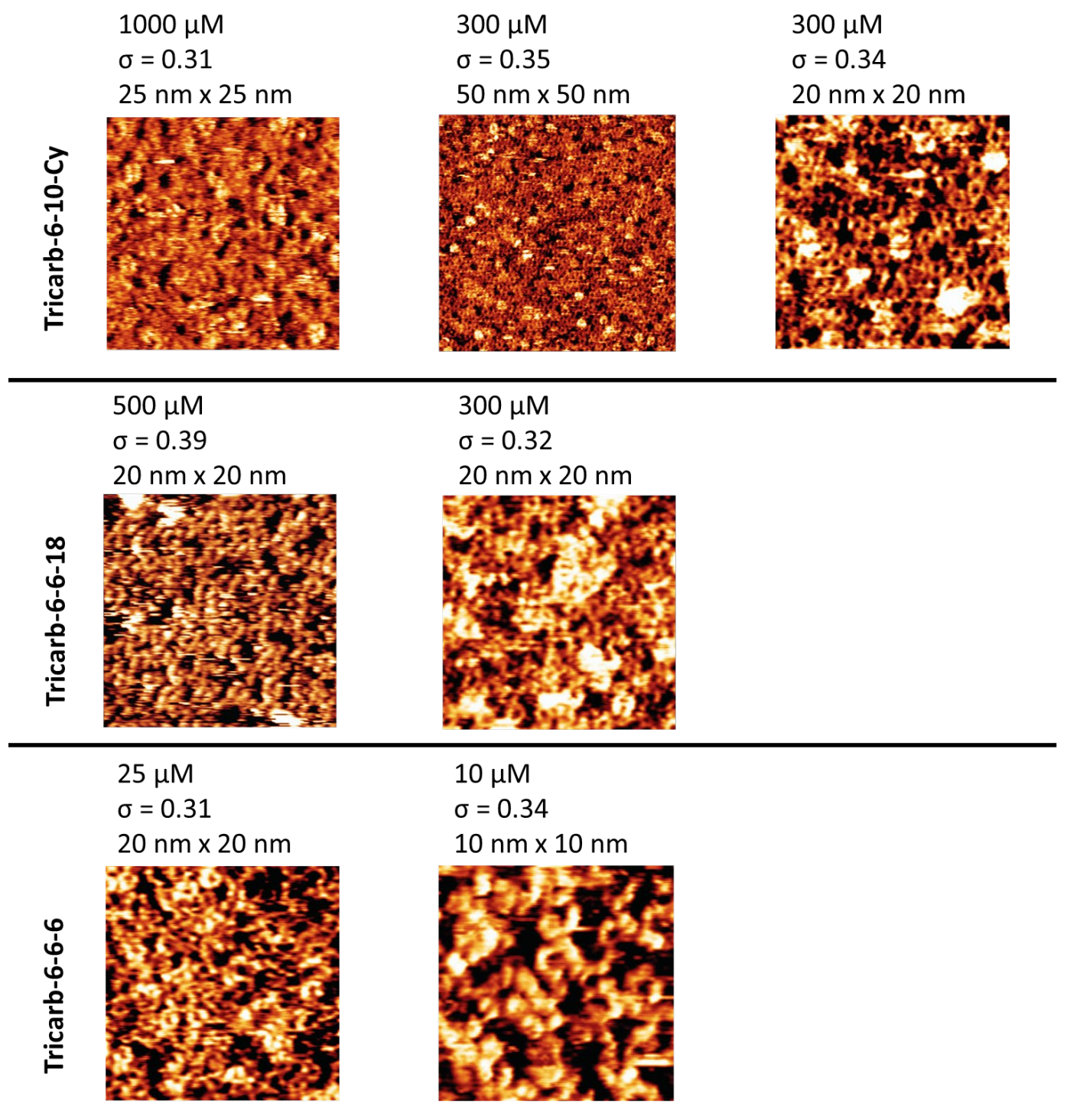




\section{S3. Force field parameterization}

\section{Parametrization of tricarbazolo triazolophane macrocycle}

The force field parameters were developed following the CHARMM methodology. ${ }^{2}$ Due to the large size of the tricarb macrocycle, a divide and conquer strategy was applied for parametrization. The molecular structure of the tricarb consisted of three carbazole and triazole units, where triazole was linked to carbazole either via ' $\mathrm{CC}$ ' or ' $\mathrm{CN}$ ' bond (Fig. S1). The initial parameters were obtained from CHARMM General Force Field (CgenFF) that already included parameters for a wide range of organic molecules, including many heterocycles. Only the parameters, which were not present in the CHARMM27 parameter list, were fitted. In this case, the parameters connecting the triazole and carbazole units were optimized. The stepwise schematic of parametrization is shown in Figure S2. A detailed discussion of the parametrization procedure had been reported in one of our recent report. ${ }^{3}$ Once, the parameters of dimer units were fitted, the full tricarb molecule was then built based on the transferability of the parameters. The charge adjustment was done by absorbing $\mathrm{H}$ charge on the heavy atom connected in order to develop the full tricarb parameters. The parameters for the alkyl substituted tricarb systems, e.g., tricarb-1-11, tricarb-6-6-6, and tricarb-10-10-10 were developed using the parameters obtained for the parent tricarb molecule.

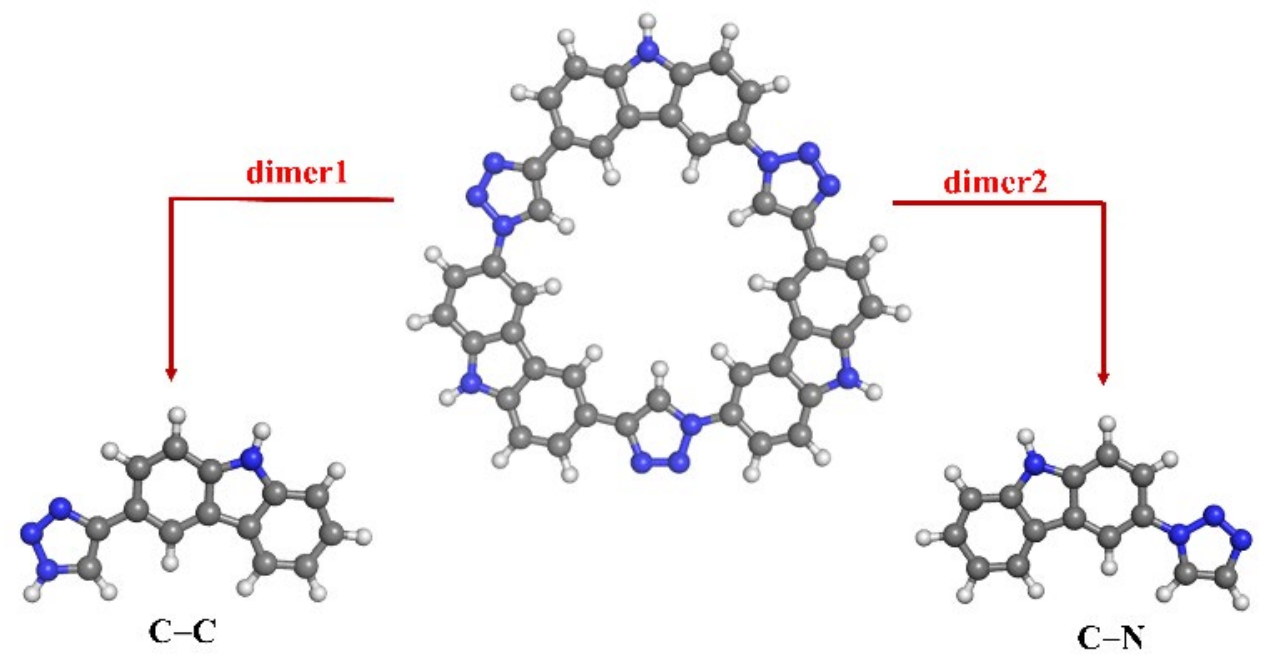

Figure S1. Dividing the tricarb macrocycle into two units which are used for force field parametrization. 


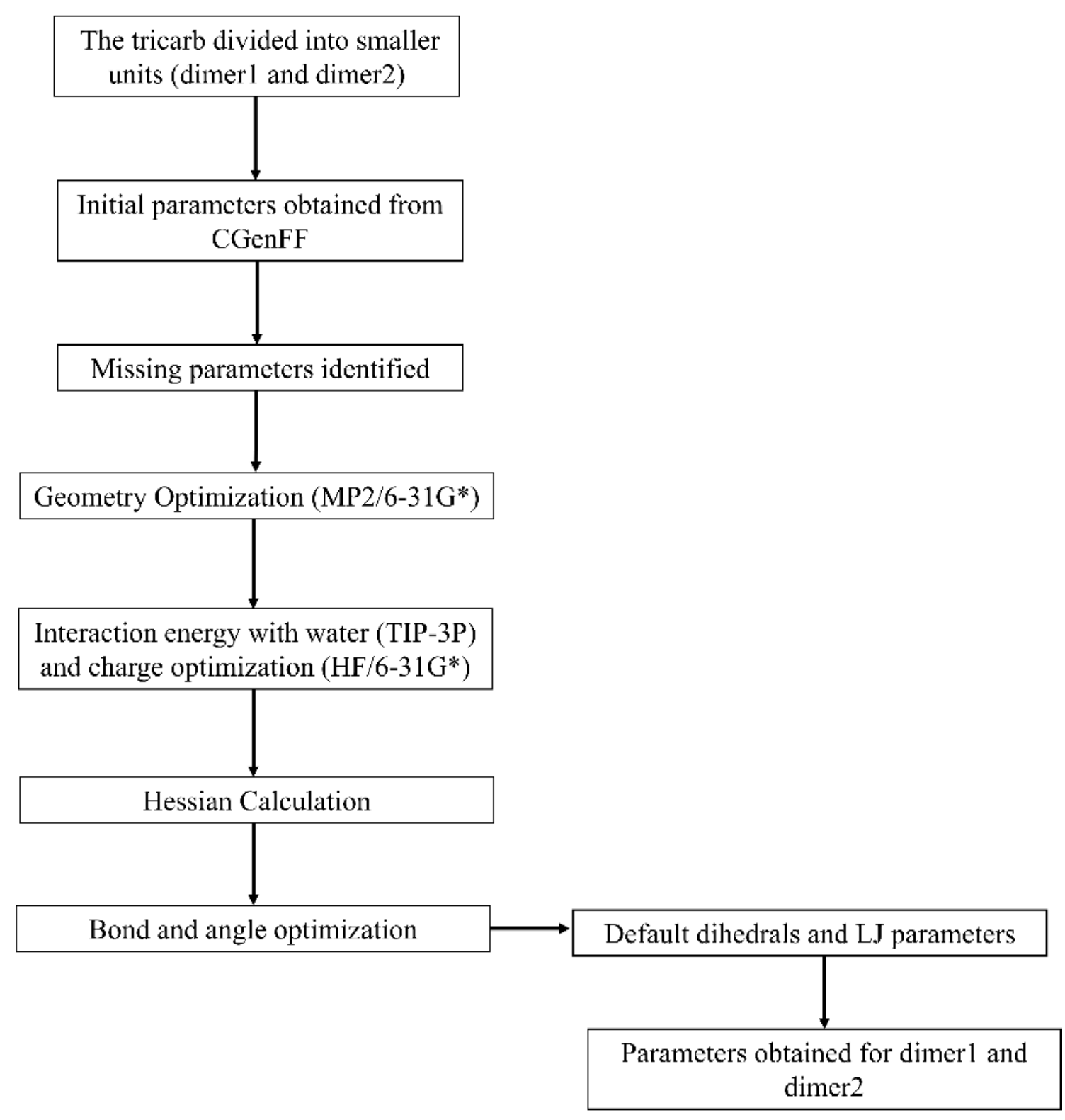

Figure S2. Parametrization scheme adopted following CHARMM methodology. ${ }^{2}$ 


\section{S4. Additional information on the design and conditions of molecular dynamics simulations}

Table S4. Simulation details of tricarb macrocycles on HOPG starting from honeycomb structure

\begin{tabular}{|l|l|l|l|l|}
\hline Tricarb species & $\begin{array}{l}\text { Number } \\
\text { Macrocycles }\end{array}$ & Solvent & Total Atoms & Sim. Time (ns)* \\
\hline tricarb-10-10-10 & 52 & TCB & 135532 & 200 \\
\hline tricarb-6-6-6 & 52 & TCB & 126604 & 200 \\
\hline tricarb-1-1-1 & 52 & TCB & 110764 & 200 \\
\hline tricarb-10-10-10 & 52 & Toluene & 172075 & 200 \\
\hline tricarb-6-6-6 & 52 & Toluene & 158713 & 200 \\
\hline tricarb-1-1-1 & 52 & Toluene & 138718 & 200 \\
\hline tricarb-10-10-10 & 52 & -- & 55360 & 98 \\
\hline tricarb-6-6-6 & 52 & -- & 53488 & 139 \\
\hline tricarb-1-1-1 & 52 & -- & 51148 & 400 \\
\hline
\end{tabular}

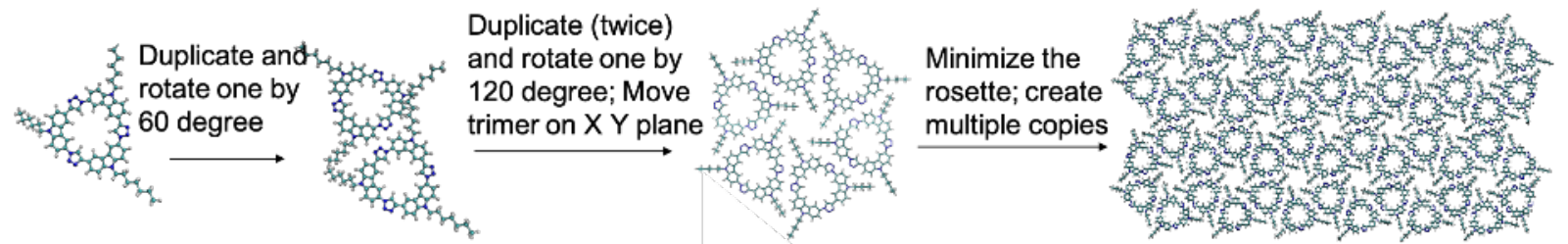

Figure S3. Honeycomb structure preparation for MD simulations. Two tricarb molecules, rotated $60^{\circ}$ relative to each other, interact via four hydrogen bonds. The dimer was duplicated twice to form a six membered ring, which was energy minimized, then duplicated to form the honeycomb structure. The unit cell size was based on STM results. ${ }^{4}$ 


\section{S5. Final states of MD simulations}
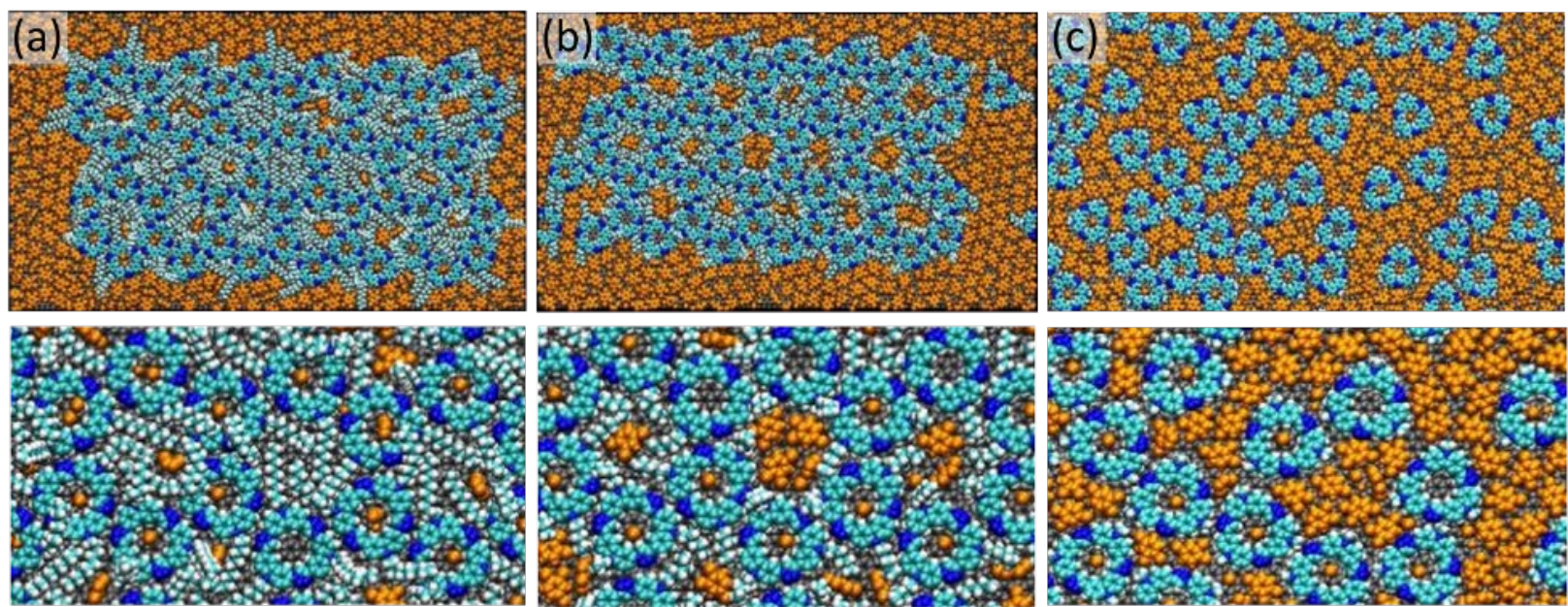

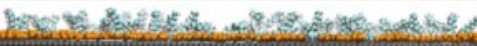
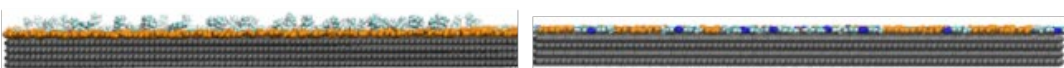

Figure S4. Top view (top and center) and side view (bottom) snapshots of MD simulations of (a) tricarb-10-10-10, (b) tricarb-6-6-6, and (c) tricarb-1-1-1 in TCB solvent on HOPG. Co-adsorbed TCB solvent is shown in orange, while other TCB molecules are omitted. Simulations time: 200 ns. We note that after this simulation period, (a) tricarb-10-10-10 retains near-perfect honeycomb packing, (b) tricarb-6-6-6 retains honeycomb packing at the center of the domain, but the domain edges begin to lose order, and (c) tricarb-1-1-1 becomes completely disordered. Porous features are present in both the honeycomb and the disordered structures. Some features within the pores are intermittently (and inconsistently) observed by STM which suggests dynamic behavior too fast to observe on the timescale of STM. Simulating tricarb self-assembly with MD simulations, which has sub-nanosecond resolution, has revealed that the pore region is an active place for transient and rapid alkyl chain (tricarb peripheral groups) and solvent molecule adsorption and desorption. 

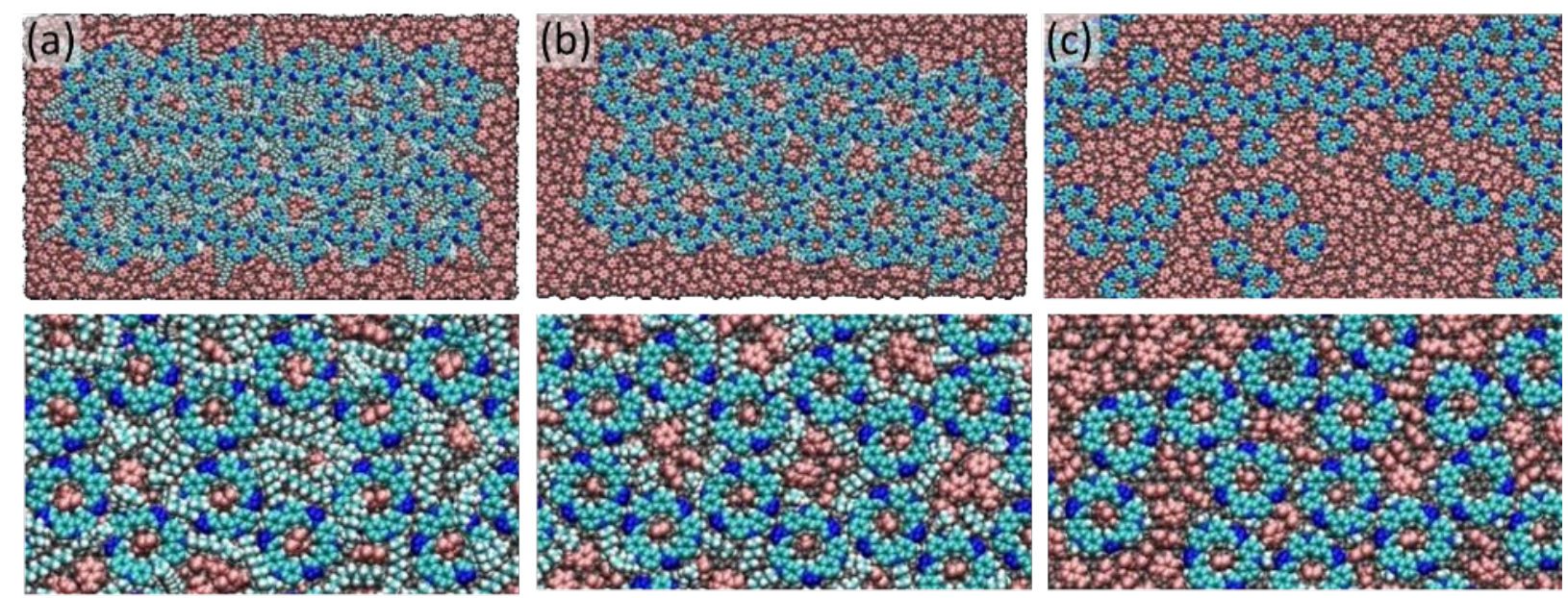

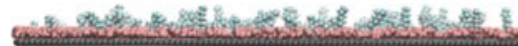
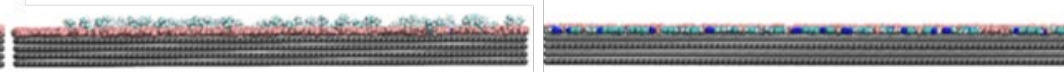

Figure S5. Top view (top and center) and side view (bottom) snapshots of MD simulations of (a) tricarb-10-10-10, (b) tricarb-6-6-6, and (c) tricarb-1-1-1 in toluene on HOPG. Co-adsorbed toluene solvent is shown in pink, while other toluene molecules are omitted. Simulations time: 200 ns. In this case, (a) tricarb-10-10-10 and (b) tricarb-6-6-6 retain near-perfect honeycomb packing, but (c) tricarb-1-1-1 shows a significant move toward disorder. 


\section{S6. Self-assembly of tricarb-10-10-10 and tricarb-6-6-6}

We note that all tricarb species studied here and in our previous work ${ }^{4}$ are prochiral and form a racemic mixture of homochiral honeycomb domains at $\pm 20^{\circ}$ relative to the low index directions of graphite. The chirality of the domains can be determined by these growth directions or by high resolution imaging of the three apices of the carbazole sub-units.
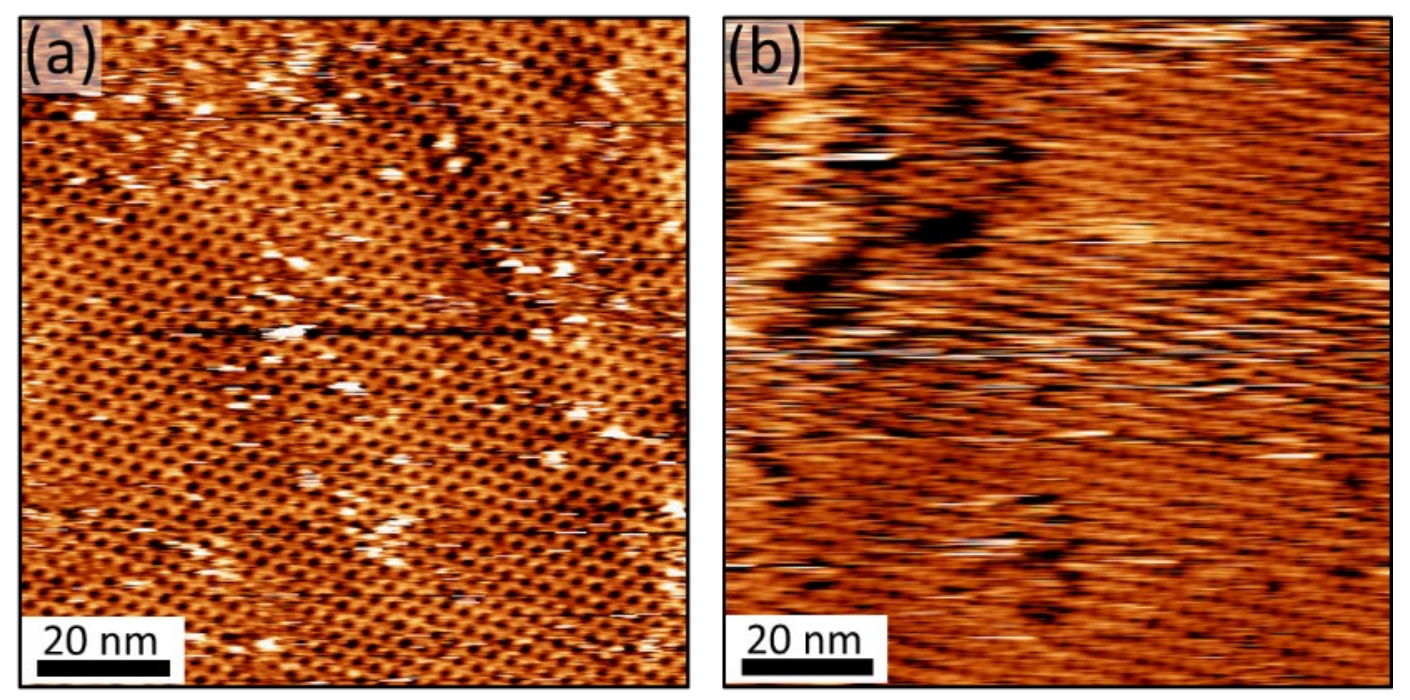

Figure S6. Tricarb-10-10-10 (solvent: TCB; room temperature) at (a) $150 \mu \mathrm{M}$ and (b) $3 \mathrm{mM}$. At both concentrations, only honeycomb is observed. Scanning conditions: (a) $I_{t}=0.20 \mathrm{nA}, V_{\text {sample }}=$ $-0.8 \mathrm{~V}$; (b) $I_{t}=0.50 \mathrm{nA}, V_{\text {sample }}=-1.0 \mathrm{~V}$.
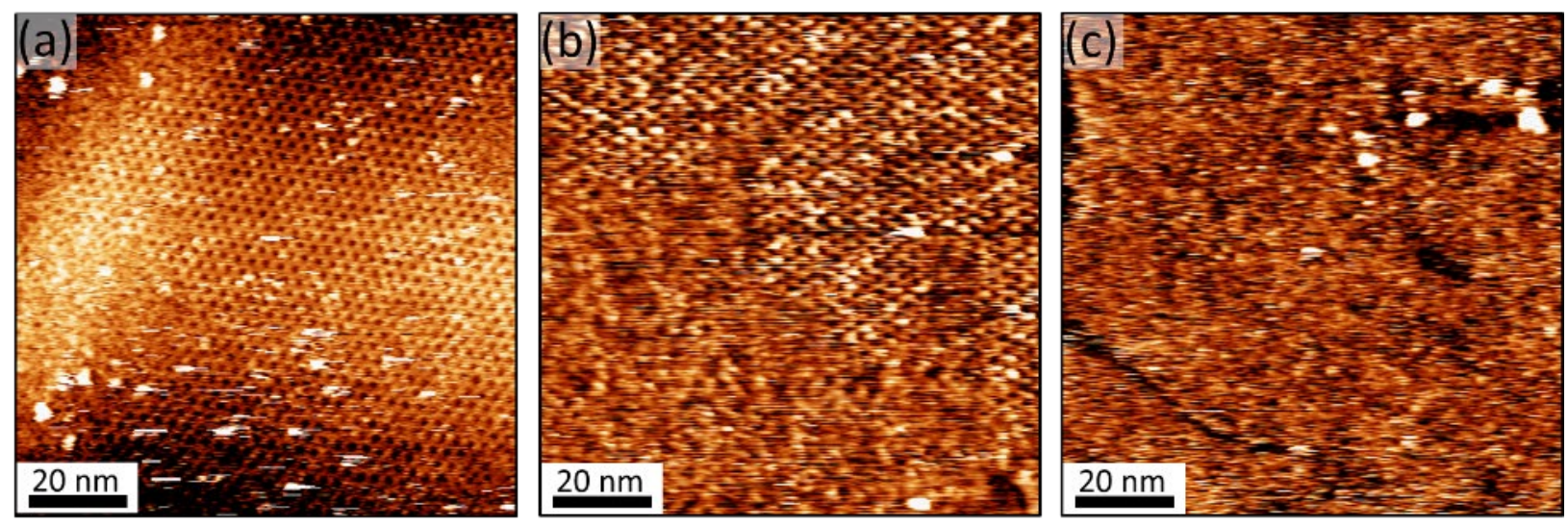

Figure S7. STM images of Tricarb-6-6-6 in TCB at room temperature. (a) At $3 \mu \mathrm{M}$, mostly honeycomb is present with some small areas of disordered structure. (b) At $25 \mu \mathrm{M}$, over $50 \%$ of the surface is disordered. (c) At $100 \mu \mathrm{M}$, only the disordered structure is observed. Scanning conditions: (a) $I_{t}=0.15 \mathrm{nA}, V_{\text {sample }}=-0.7 \mathrm{~V}$; (b) $I_{t}=0.10 \mathrm{nA}, V_{\text {sample }}=-0.4 \mathrm{~V}$; (c) $I_{t}=0.80 \mathrm{nA}$, $V_{\text {sample }}=-0.7 \mathrm{~V}$. 
S7. Variable temperature self-assembly of tricarb-6-6-18 and tricarb-6-10-Cy
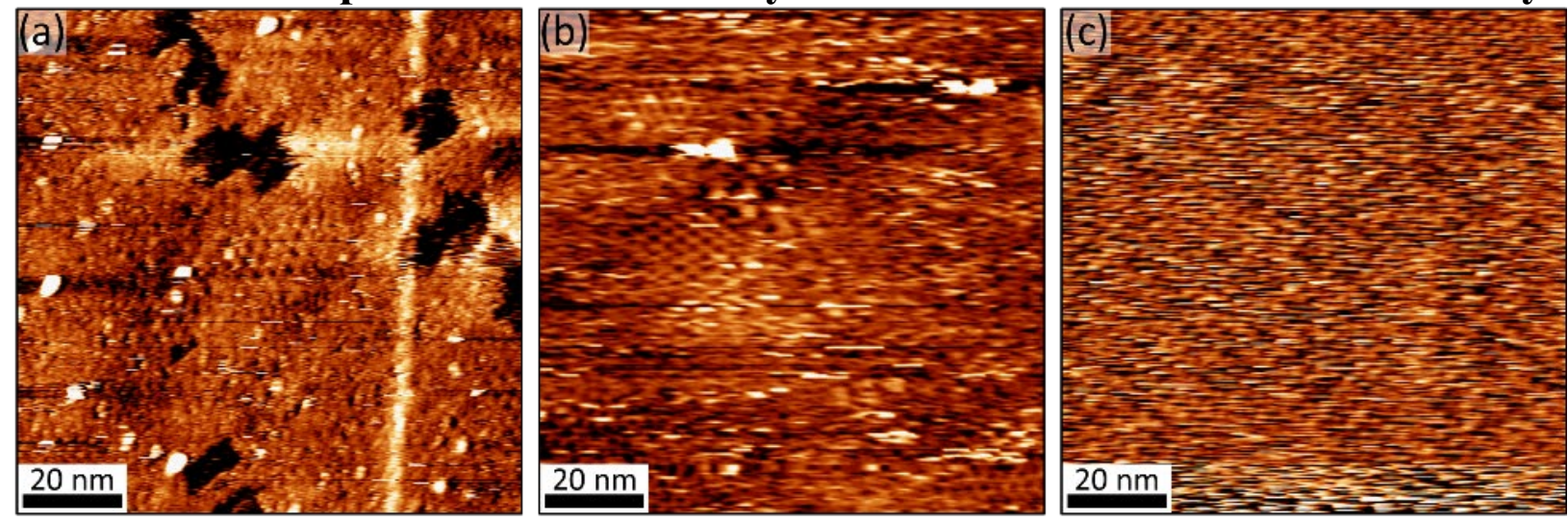

Figure S8. Three different samples of tricarb-6-6-18 (300 $\mu \mathrm{M}$, solvent: TCB) deposited at three surface temperatures $\left(\mathrm{a}: 8^{\circ} \mathrm{C}\right.$, b: $20^{\circ} \mathrm{C}$ c: $50{ }^{\circ} \mathrm{C}$ ). More honeycomb domains are present when deposited at $50{ }^{\circ} \mathrm{C}$ (c), and more disordered domains are present when deposited at $8{ }^{\circ} \mathrm{C}$ (a). Scanning conditions: (a) $I_{t}=0.40 \mathrm{nA}, V_{\text {sample }}=-0.7 \mathrm{~V}$; (b) $I_{t}=0.50 \mathrm{nA}, V_{\text {sample }}=-0.7 \mathrm{~V}$; (c) $I_{t}=0.40 \mathrm{nA}, V_{\text {sample }}=-0.7 \mathrm{~V}$. 
(a) Deposition temperature at $50^{\circ} \mathrm{C}$
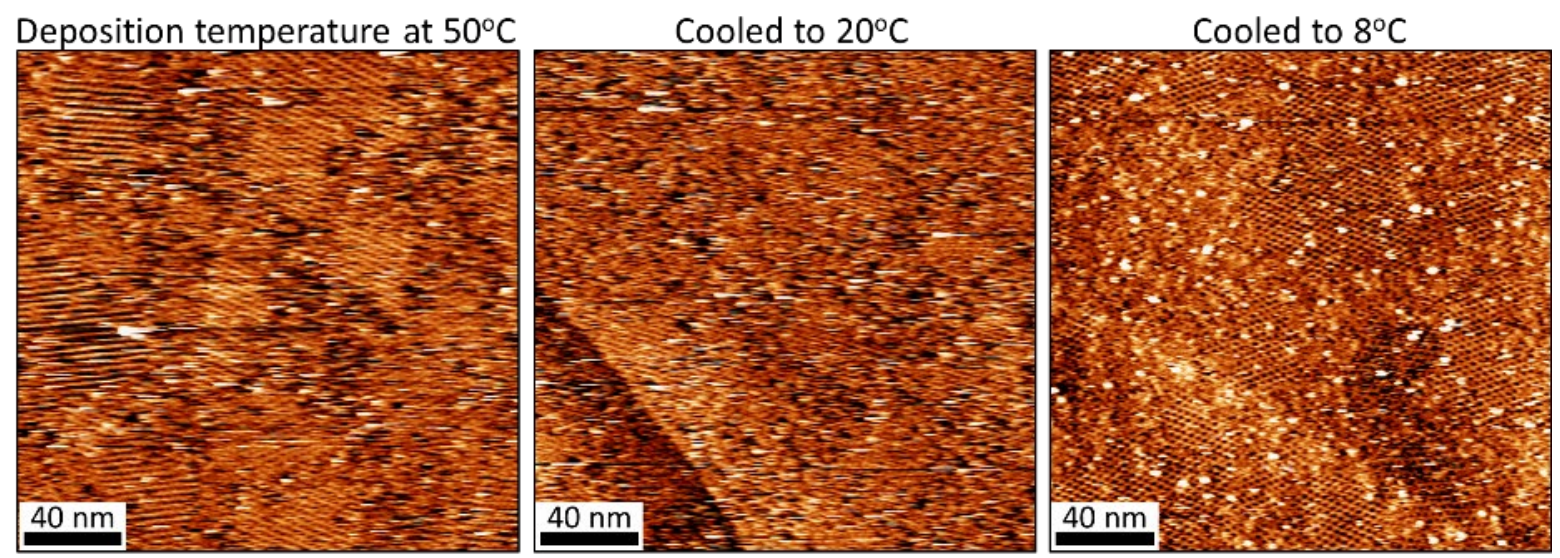

(b)
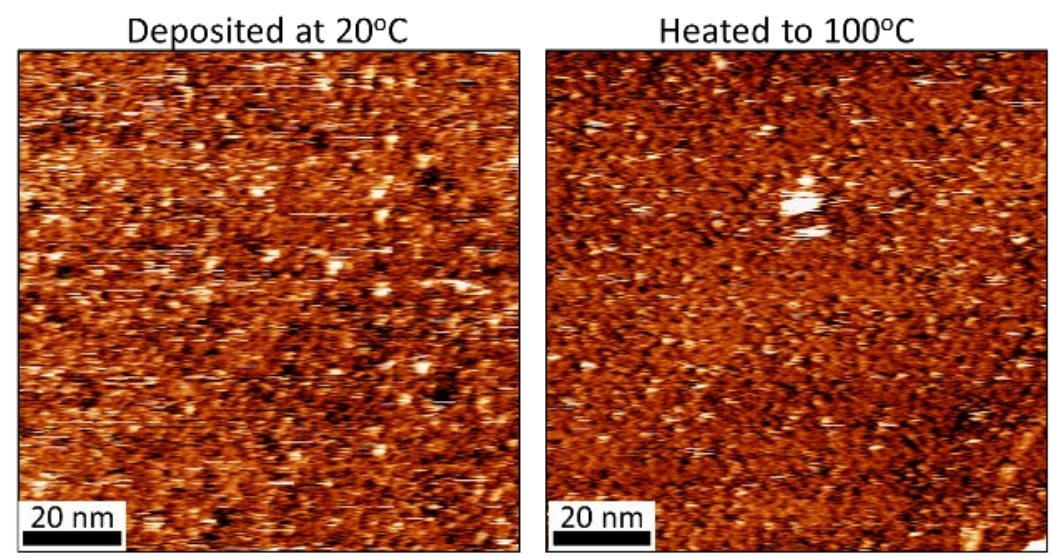

Figure S9. (a) From left to right: tricarb-6-10-Cy (300 $\mu \mathrm{M}$, solvent: TCB) deposited at $50{ }^{\circ} \mathrm{C}$ and subsequently cooled to $20^{\circ} \mathrm{C}$ and $8{ }^{\circ} \mathrm{C}$. No change in honeycomb: disordered ratio as sample is cooled. Scanning conditions: left: $I_{t}=0.15 \mathrm{nA}, V_{\text {sample }}=-0.7 \mathrm{~V}$; center: $I_{t}=0.10 \mathrm{nA}, V_{\text {sample }}=$ $-0.7 \mathrm{~V}$; right: $I_{t}=0.10 \mathrm{nA}, V_{\text {sample }}=-0.7 \mathrm{~V}$. (b) Left: tricarb-6-10-Cy $(1 \mathrm{mM}$, solvent: TCB) deposited at $20^{\circ} \mathrm{C}$. Only disordered is observed. Right: after heating at $100{ }^{\circ} \mathrm{C}$ for 10 minutes and cooling to $30^{\circ} \mathrm{C}$ at a rate of $-1{ }^{\circ} \mathrm{C} / \mathrm{min}$ (warm TCB was constantly added while heating to maintain sample volume). No change is observed after heating; only disordered is observed. Scanning conditions: left: $I_{t}=1.20 \mathrm{nA}, V_{\text {sample }}=-0.7 \mathrm{~V}$; right: $I_{t}=2.30 \mathrm{nA}, V_{\text {sample }}=-0.7 \mathrm{~V}$. 


\section{S8. Variable solvent self-assembly of tricarb-6-6-18 and tricarb-6-10-Cy}
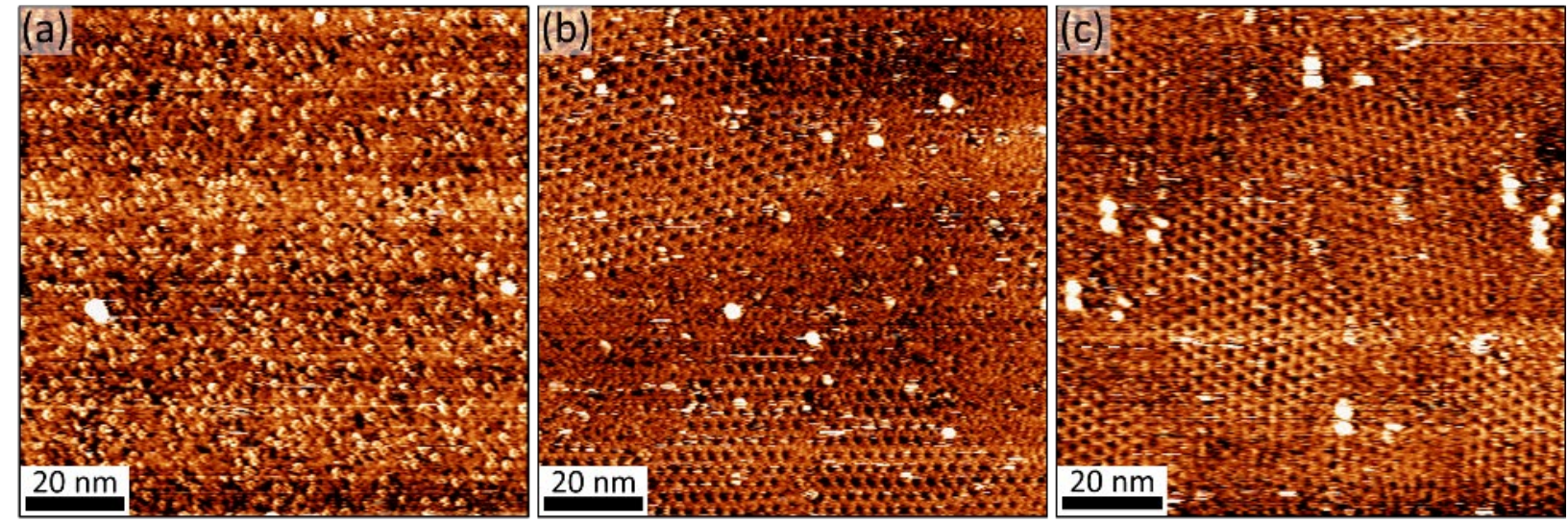

Figure S10. Three different samples of tricarb-6-6-18 $(250 \mu \mathrm{M})$ with different solvent compositions. (a) Solvent composed of 1:1 (by volume) of TCB and octanoic acid (OA). All disordered is observed. (b) Solvent composed of only TCB. Both disordered and honeycomb are present. (c) Solvent composed of 1:1 (by volume) of TCB and toluene. Surface is primarily covered with honeycomb. Note that toluene is volatile and evaporates within 10's of seconds after deposition. The concentration of this sample while scanning is $500 \mu \mathrm{M}$. Scanning conditions: (a) $I_{t}=0.10 \mathrm{nA}, V_{\text {sample }}=-0.7 \mathrm{~V}$; (b) $I_{t}=0.40 \mathrm{nA}, V_{\text {sample }}=-0.7 \mathrm{~V}$; (c) $I_{t}=0.20 \mathrm{nA}$, $V_{\text {sample }}=-0.7 \mathrm{~V}$. 
(a) Before toluene addition

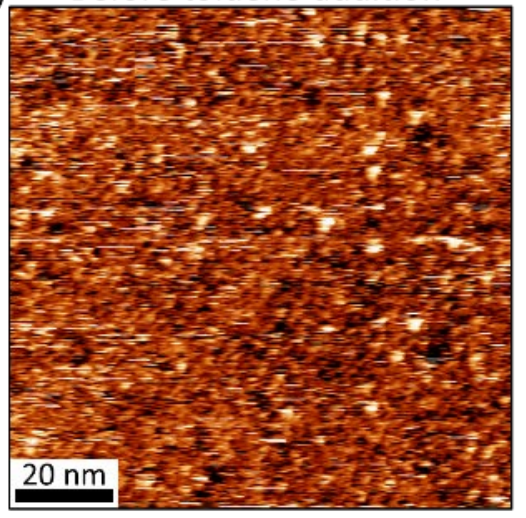

(b)

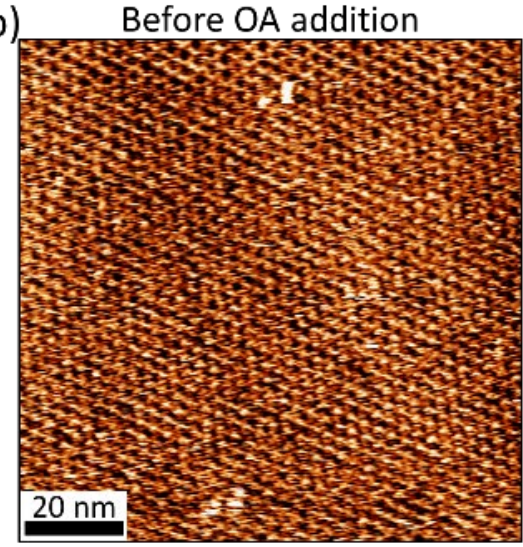

After in situ toluene addition

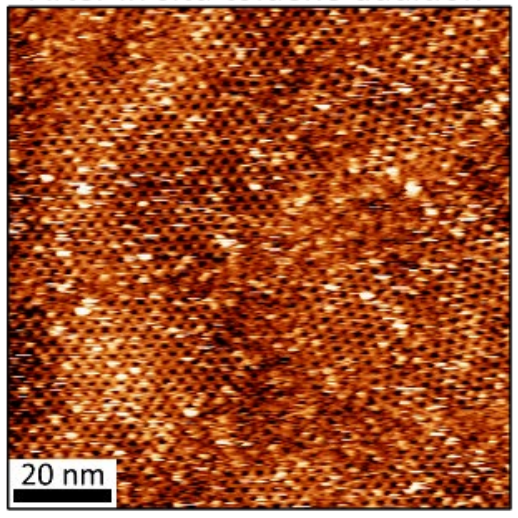

After in situ OA addition

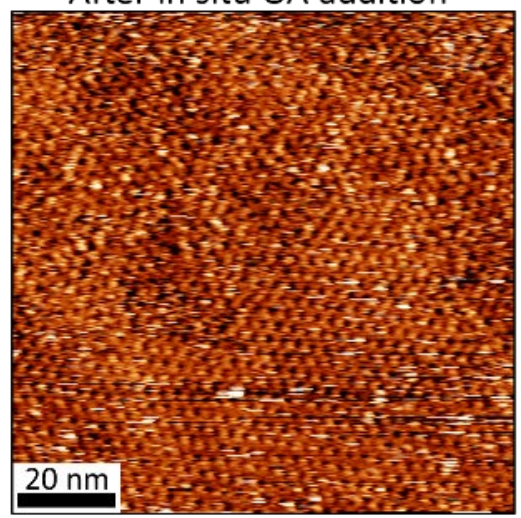

Ex situ OA addition

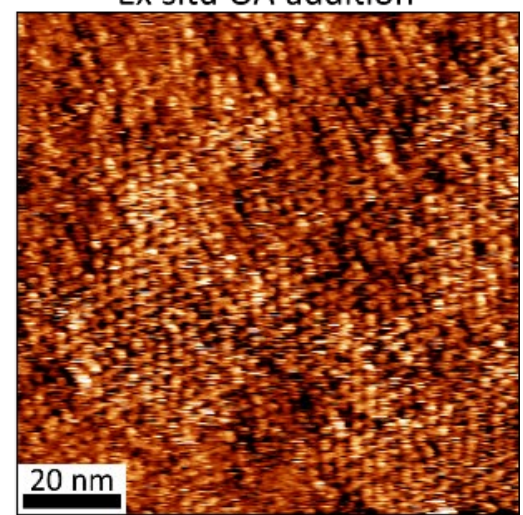

Figure S11. (a) tricarb-6-10-Cy $(1 \mathrm{mM})$. Left: before the addition of toluene, only disordered is observed. Right: after $16 \mu \mathrm{L}$ of toluene have been added in situ to the sample subsequent evaporation of toluene (final tricarb conc.: $1 \mathrm{mM}$ ). Over $70 \%$ of surface is now covered with honeycomb even though the final sample concentration is still $1 \mathrm{mM}$. Scanning conditions: left: $I_{t}=1.20 \mathrm{nA}, V_{\text {sample }}=-0.7 \mathrm{~V}$; right: $I_{t}=0.80 \mathrm{nA}, V_{\text {sample }}=-0.7 \mathrm{~V}$. (b) tricarb-6-10-Cy. Left: only honeycomb is observed $(10 \mu \mathrm{M})$. Center: after addition of OA in situ (final tricarb conc.: $5 \mu \mathrm{M})$, no difference in honeycomb coverage is observed. Right: ex situ addition of OA (1:1 TCB by volume, tricarb conc.: $10 \mu \mathrm{M})$. Both honeycomb and disordered is observed, but honeycomb is dominant. Scanning Conditions: left: $I_{t}=0.20 \mathrm{nA}, V_{\text {sample }}=-0.8 \mathrm{~V}$; center: $I_{t}=0.60 \mathrm{nA}, V_{\text {sample }}=$ $-0.8 \mathrm{~V}$; right: $I_{t}=0.08 \mathrm{nA}, V_{\text {sample }}=-0.5 \mathrm{~V}$. 


\section{S9. Tricarb-tricarb interaction energies}
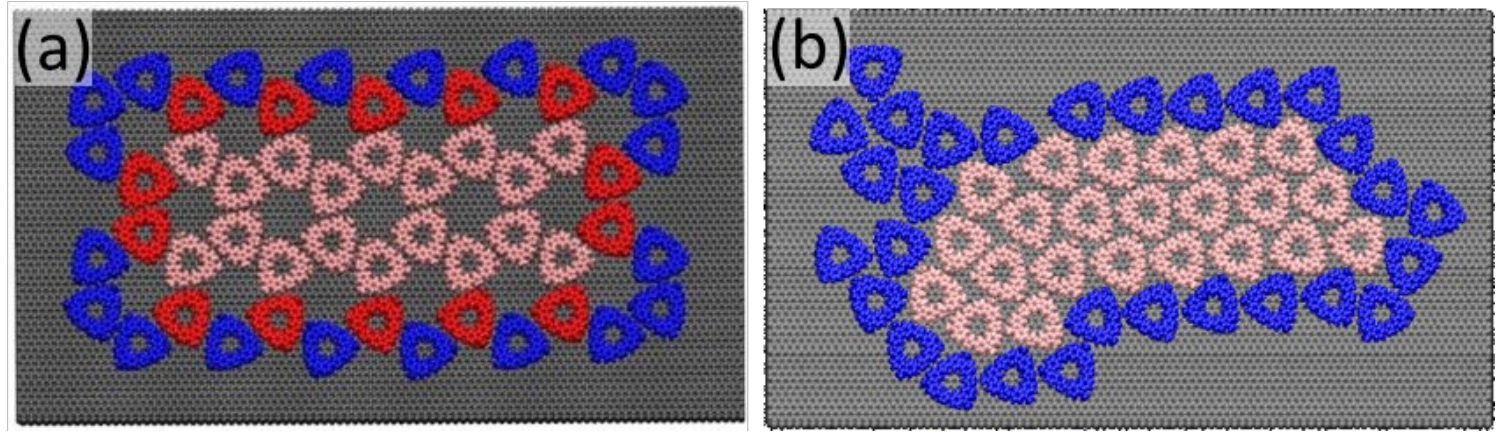

Figure S12. MD simulation snapshots of tricarb-1-1-1 adsorbed on HOPG surface (no solvent) forming (a) honeycomb structure and (b) high-density structure. Molecules on the edges of a structure are in blue. In the honeycomb structure, molecules in red are on the edges, but they have three nearest neighbors as those in pink. First, the entire system was minimized via steepest descent algorithm followed with conjugate gradient algorithm; total potential energy was obtained as $P E_{0}$. Then, the target molecule $i$ was moved along the z-axis for $2.5 \mathrm{~nm}$ (beyond the cut-off range of the immunization); this system was minimized in a similar manner then total potential energy was obtained as $P E_{i}$. Therefore, the energy needed to remove the $i$-th molecule from surface is $P E_{i}-$ $P E_{0}$. To avoid edge effects, only molecules in the bulk of each structure (pink and red) were included in the calculation. The average energy needed to remove one tricarb-1-1-1 molecule from (a) honeycomb or (b) high-density packing structure of 52 tricarb-1-1-1 molecules was calculated via GROMACS to be $537.5 \pm 5.7 \mathrm{~kJ} / \mathrm{mol}(\mathrm{N}=32$ pink and red molecules, error represents \pm 1 standard deviation) or $499.5 \pm 7.7 \mathrm{~kJ} / \mathrm{mol}(\mathrm{N}=23$ pink molecules, error represents \pm 1 standard deviation), respectively. Each pink molecule in the structures shown in panels (a) and (b) was tested individually and the average and one standard deviation of those results is reported here. The major contribution $(\sim 85 \%)$ of the total intermolecular energy is VDW interaction (Table S5).

Table S5. Energy contribution, separated as vdW and electrostatic interactions, for tricarb-1-1-1 adsorbed on HOPG surface (no solvent).

\begin{tabular}{|c|c|c|c|c|}
\hline Patterns & $\mathrm{vdW}\left(\mathrm{kJ} \cdot \mathrm{mol}^{-1}\right)^{a}$ & $\mathrm{vdW}\left(\mathrm{kJ} \cdot \mathrm{mol}^{-1} \cdot \mathrm{nm}^{-2}\right)^{b}$ & $\begin{array}{c}\text { Electrostatic } \\
\left(\mathrm{kJ} \cdot \mathrm{mol}^{-1}\right)^{a}\end{array}$ & $\begin{array}{c}\text { Electrostatic } \\
\left(\mathrm{kJ} \cdot \mathrm{mol}^{-1} \cdot \mathrm{nm}^{-2}\right)^{b}\end{array}$ \\
\hline Honeycomb & -338.5 & -94.8 & -47.88 & -13.4 \\
\hline $\begin{array}{c}\text { High-density } \\
\text { packing }\end{array}$ & -521.2 & -161.6 & -76.54 & -23.7 \\
\hline
\end{tabular}

\footnotetext{
${ }^{a} \mathrm{~kJ}$ per mole of tricarb.

${ }^{b} \mathrm{~kJ}$ per mole $\cdot \mathrm{nm}^{2}$, calculated by multiplying previous column by surface density of tricarb for that phase: $\sigma_{\text {honeycomb }}=0.28$ tricarb $/ \mathrm{nm}^{2}$ or $\sigma_{\text {disordered }}=0.31$ tricarb $/ \mathrm{nm}^{2}$.
} 
(a)

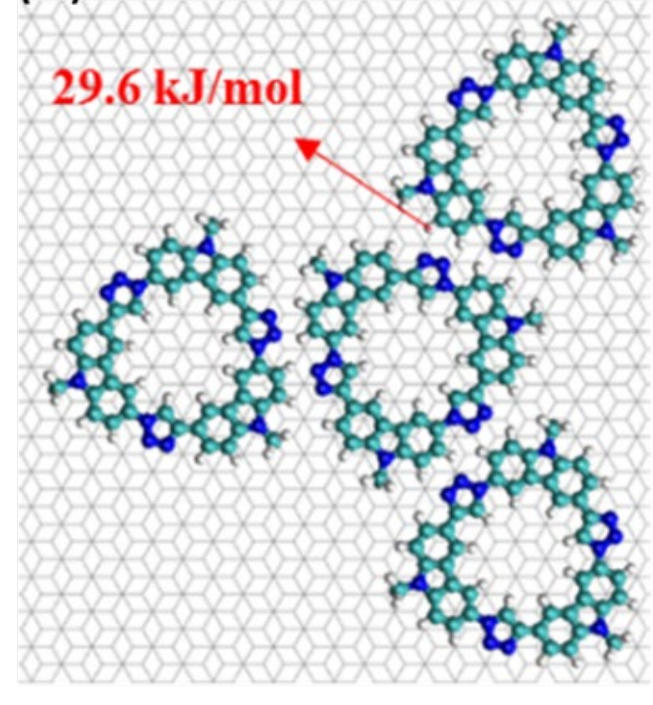

(b)

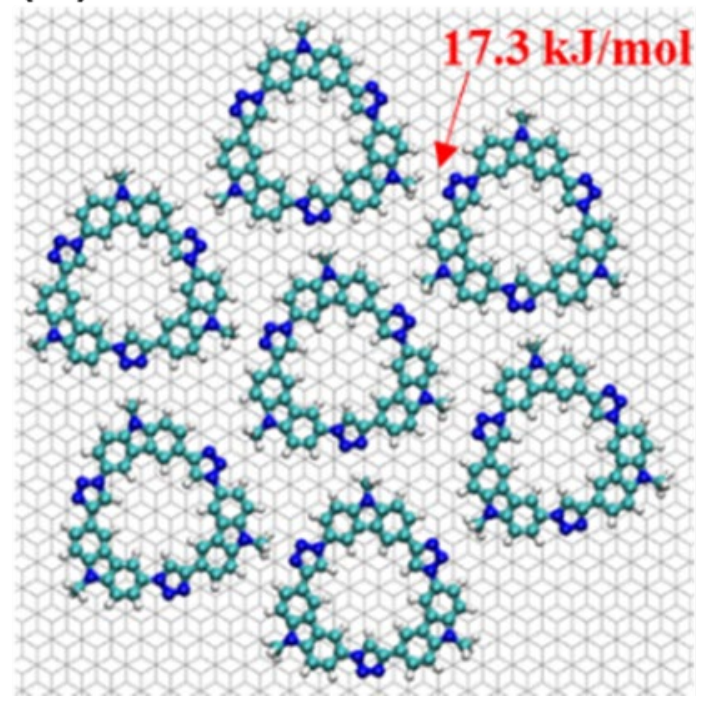

Figure S13. One tricarb-1-1-1 molecule surrounded by its closest neighbors in (a) honeycomb and (b) repeating pattern identified from three MD simulations in vacuum. The reported interaction energies are the potential energy differences between a dimer and separated tricarb molecules without HOPG surface. Since these potential energies were extracted using the conjugate gradient algorithm in Gromacs, molecules did not undergo major internal structural changes after minimization. Interaction energy calculated in this way represent the sum of electrostatic and VDW interactions between two tricarb molecules. Though individual of triazolecarbazole hydrogen bonding yield lower potential energy, the sum of six tip-to-bottom interaction is lower than that of three of triazole-carbazole interactions.

We note that while these energy calculations are very efficient in vacuum, the rest of the calculations described in this work were done using explicit solvent. In a recent work at the vacuum/HOPG interface, ${ }^{3}$ tricarb-10-10-10 and tricarb-6-6-6 self-assembly was simulated by MD. In vacuum, the unit cell of honeycomb expanded (honeycomb structure was retained). The expansion was caused by the full adsorption of all peripheral alkyl chains which resulted in the breakage of carbazole-triazole contacts. ${ }^{3}$ In contrast, unit cell sizes for simulations at the solution/HOPG of tricarb-10-10-10 or tricarb-6-6-6 interface are very close to experimental values. 


\section{S10. Honeycomb deterioration facilitated by TCB insertion}

(a)
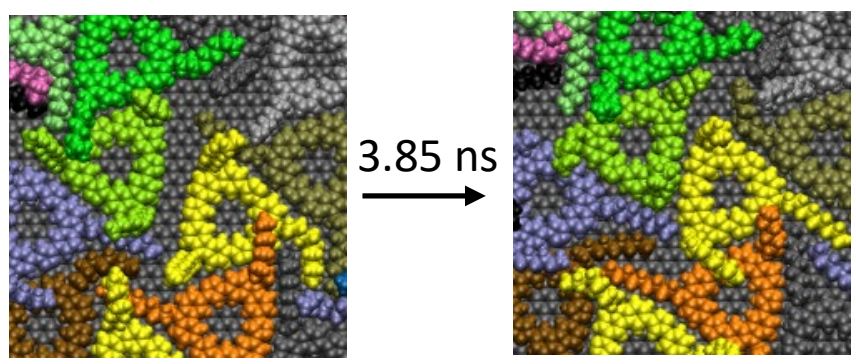

(b)
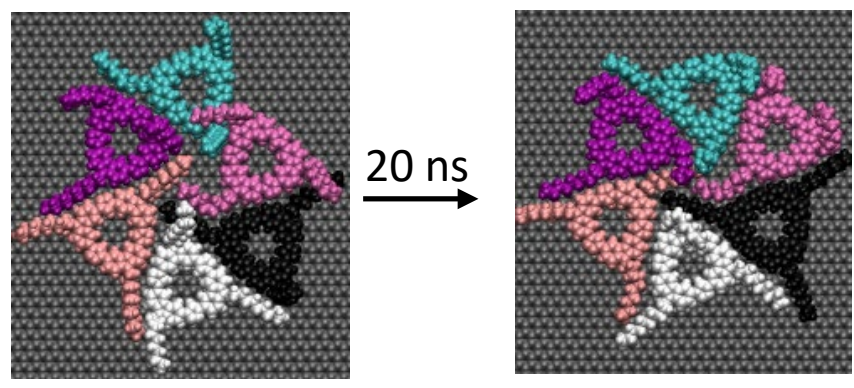

Figure S14. Loss of honeycomb structure observed in the simulation of tricarb-10-10-10. (a) A fracture between the yellow and light green macrocycles is healed in $3.85 \mathrm{~ns}$. (b) The macrocycle in cyan has broken several hydrogen bond contacts with adjacent tricarb molecules but has eventually returned after $20 \mathrm{~ns}$. TCB molecules are not shown in all the figures. 

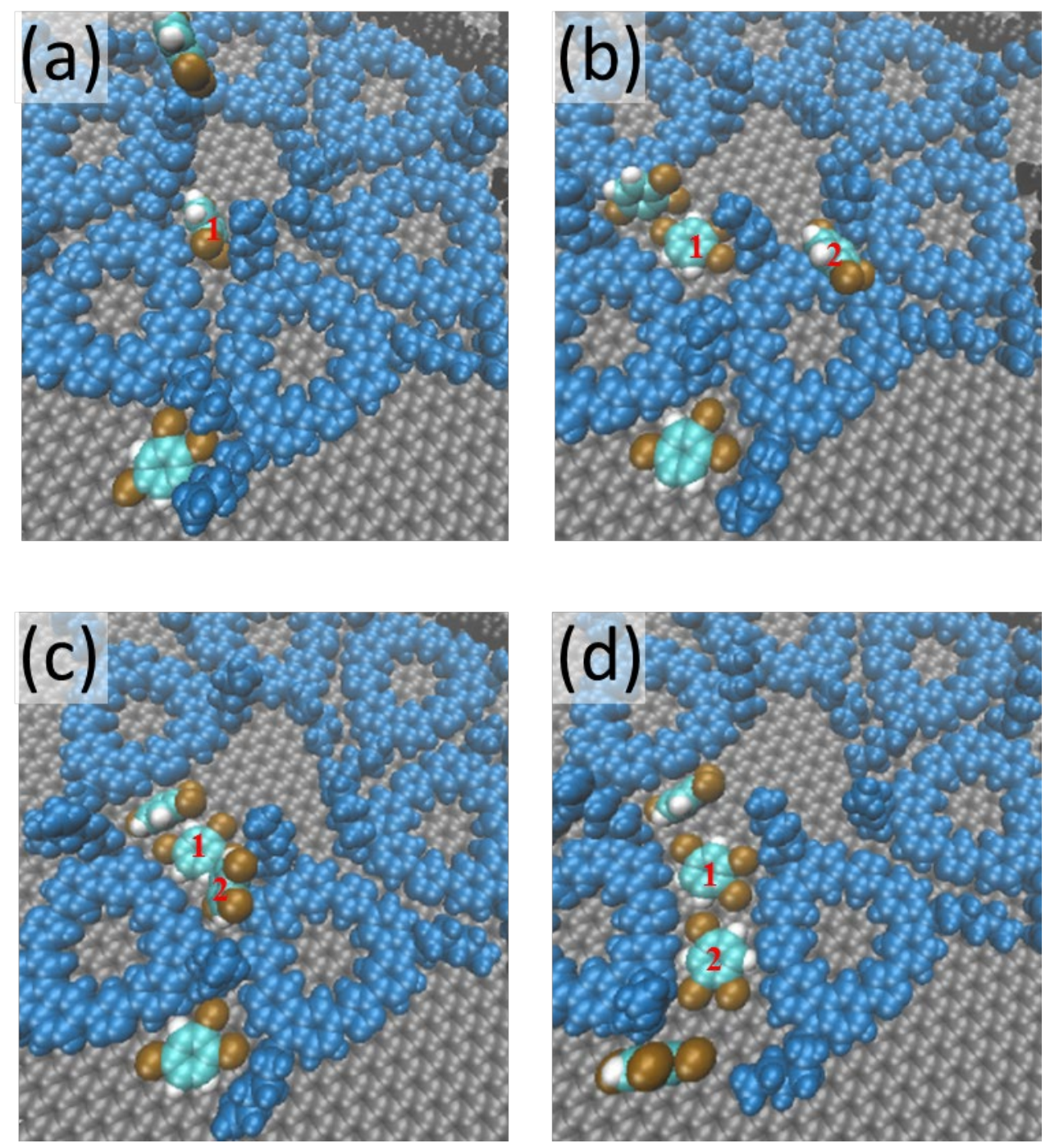

Figure S15. Loss of honeycomb structure is observed in the simulation of tricarb-6-6-6 in TCB solvent. (a) TCB1 inserts between two tricarb macrocycles and (b) after $25 \mathrm{ps,} \mathrm{fully} \mathrm{adsorbs} \mathrm{to} \mathrm{the}$ HOPG surface. In the $2.95 \mathrm{~ns}$ between (b) and (c), TCB2 approaches the tricarb-tricarb contact and begins to insert between the molecules, (d) fully adsorbing 75 ps later. 

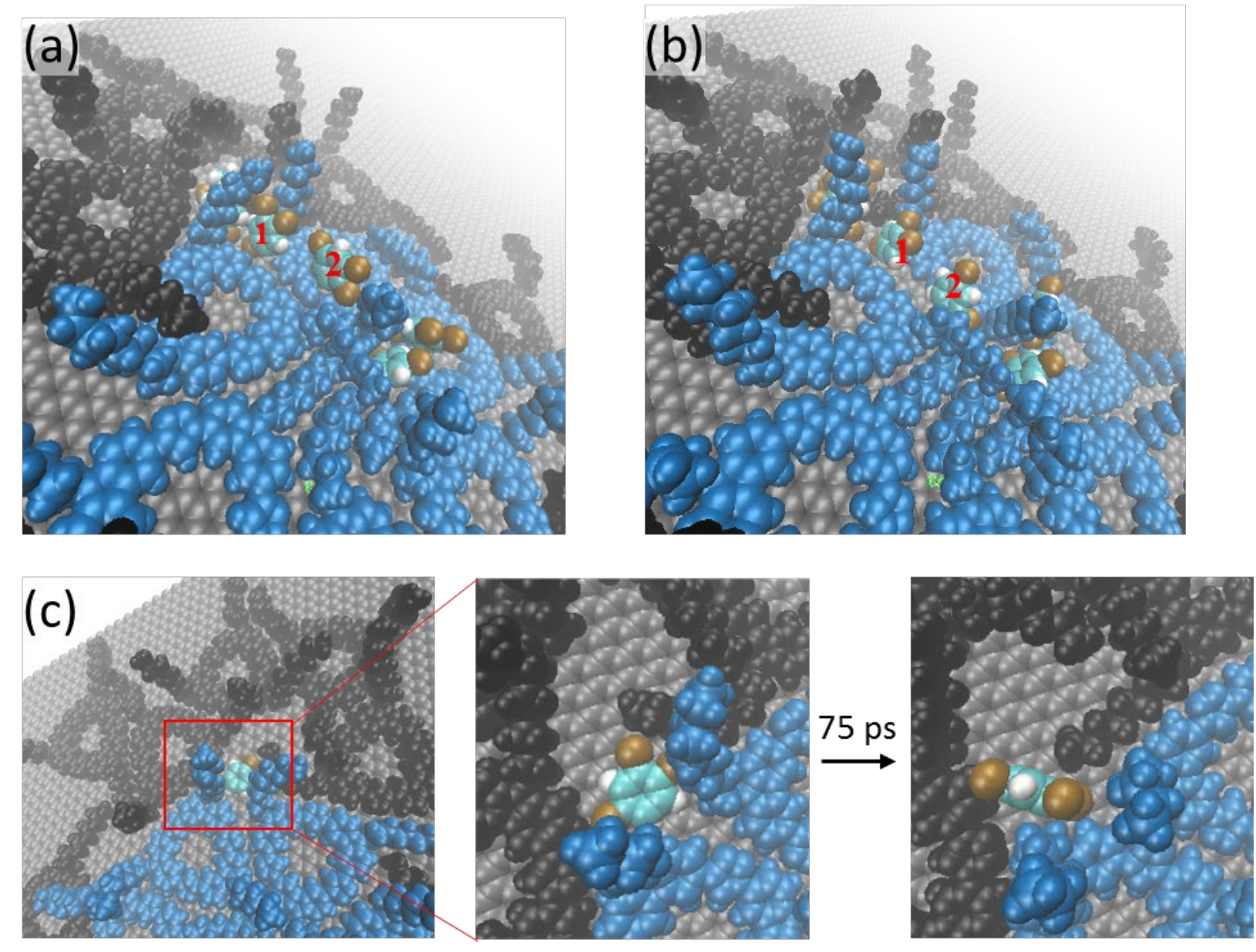

Figure S16. Two TCB molecules are identified to cause a fracture between two tricarb-10-10-10 molecules. (a) 25 ps before the fracture occur, TCB1 is adsorbed to one side of the fracturing cite with its benzene ring perpendicular to the HOPG. (b) TCB1 opens up the of triazole-carbazole hydrogen bonding of two tricarb cores, which allows for the insertion of TCB2. The fracturing site remains in this configuration for about $3 \mathrm{~ns}$, during which other TCB molecules exchange with TCB1 and TCB2. Finally, all the TCB molecules are desorbed from the fracturing site. (c) After the fracturing is healed, one TCB molecule attempts to break the of triazole-carbazole hydrogen bonding but is blocked by alkyl chains. 


\section{S11. Toluene insertion and reforming of tricarb-tricarb contacts}
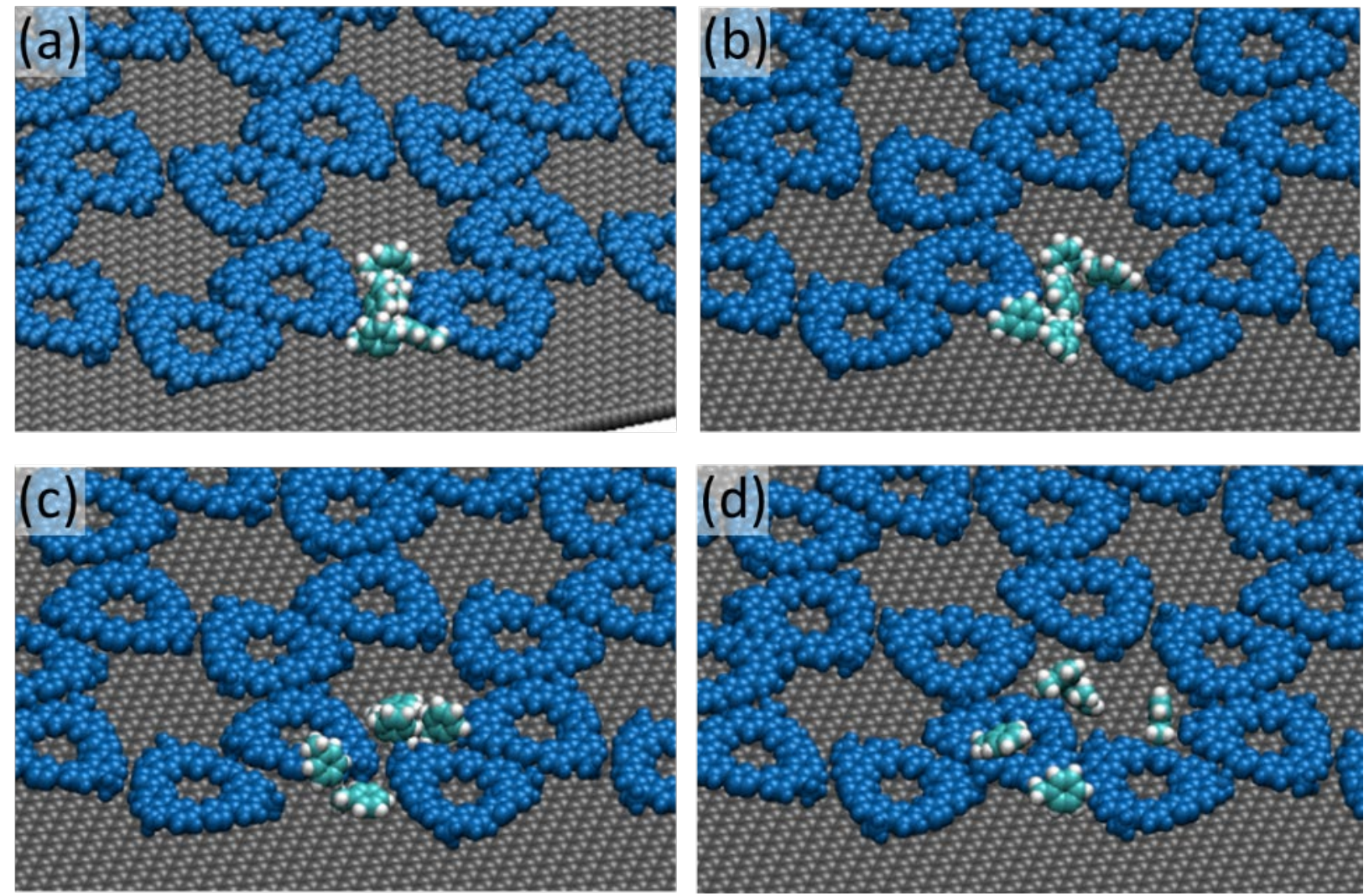

Figure S17. Self-healing event in the simulation of tricarb-1-1-1 in toluene. (a) A fracture occurs at $1 \mathrm{~ns}$ with toluene molecules inserted between two tricarb cores. (b) Over the course of the fracture's existence $(0.7 \mathrm{~ns})$, the co-adsorbed toluene molecules causing the fracture are in constant motion as opposed to forming a quasi-stable organization. (c) Then, toluene molecules desorb, and (d) tricarb molecules shift back to the honeycomb lattice. 

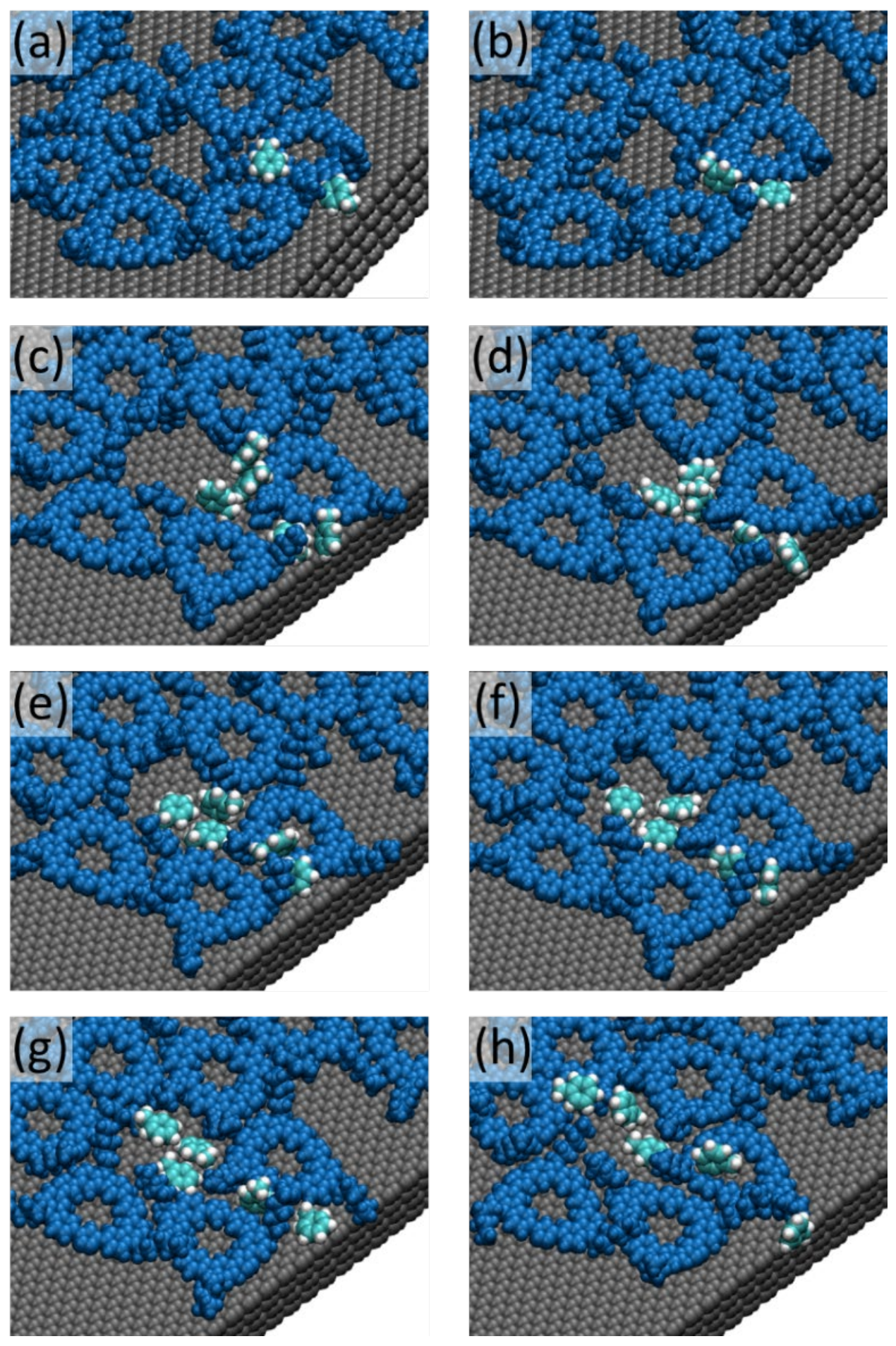

Figure S18. Self-healing event in the simulation of tricarb-6-6-6 in toluene. (a-b) Initial insertion occurs at (a) $87.85 \mathrm{~ns}$ and (b) $87.88 \mathrm{~ns}$. (c-f) The fracture remains for $3.3 \mathrm{~ns}$ during which toluene molecules around the fracturing site are constantly desorbed and re-absorbed. Snapshots (c-f) are at $91.2,91.3,91.6$, and $91.65 \mathrm{~ns}$, respectively. (g-h) The fracture starts to heal at $92 \mathrm{~ns}$ and is fully recovered at $92.25 \mathrm{~ns}$. 


\section{S12. Honeycomb to disordered progression of tricarb-1-1-1}

MD simulations in toluene are consistent with STM experiments in toluene; simulations show that toluene is a better solvent for retaining tricarb's honeycomb packing. In simulations of tricarb initially in honeycomb packing with toluene solvent, tricarb-10-10-10 and tricarb-6-6-6 preserve their honeycomb during the entire simulation period. Fractures and self-healing are observed for both systems, while self-healing is only observed for tricarb-10-10-10 in TCB. A honeycomb to disordered transition is observed for tricarb-1-1-1 due to the impact of toluene molecules. This phenomenon is similar to that observed for tricarb-1-1-1 in TCB. However, the 2-D diffusion of tricarb-1-1-1 molecules is faster in toluene than that in TCB. In toluene, tricarb-1-1-1 starts losing its honeycomb structure at $4.5 \mathrm{~ns}$ (Fig. S20), which is 10 times slower than that in TCB (Fig. S20). Also, the loss of honeycomb starts from edges, and propagate to the center of honeycomb domain. Comparing to simulations in TCB, the loss of honeycomb occurs both on the edges and middle of the honeycomb island.
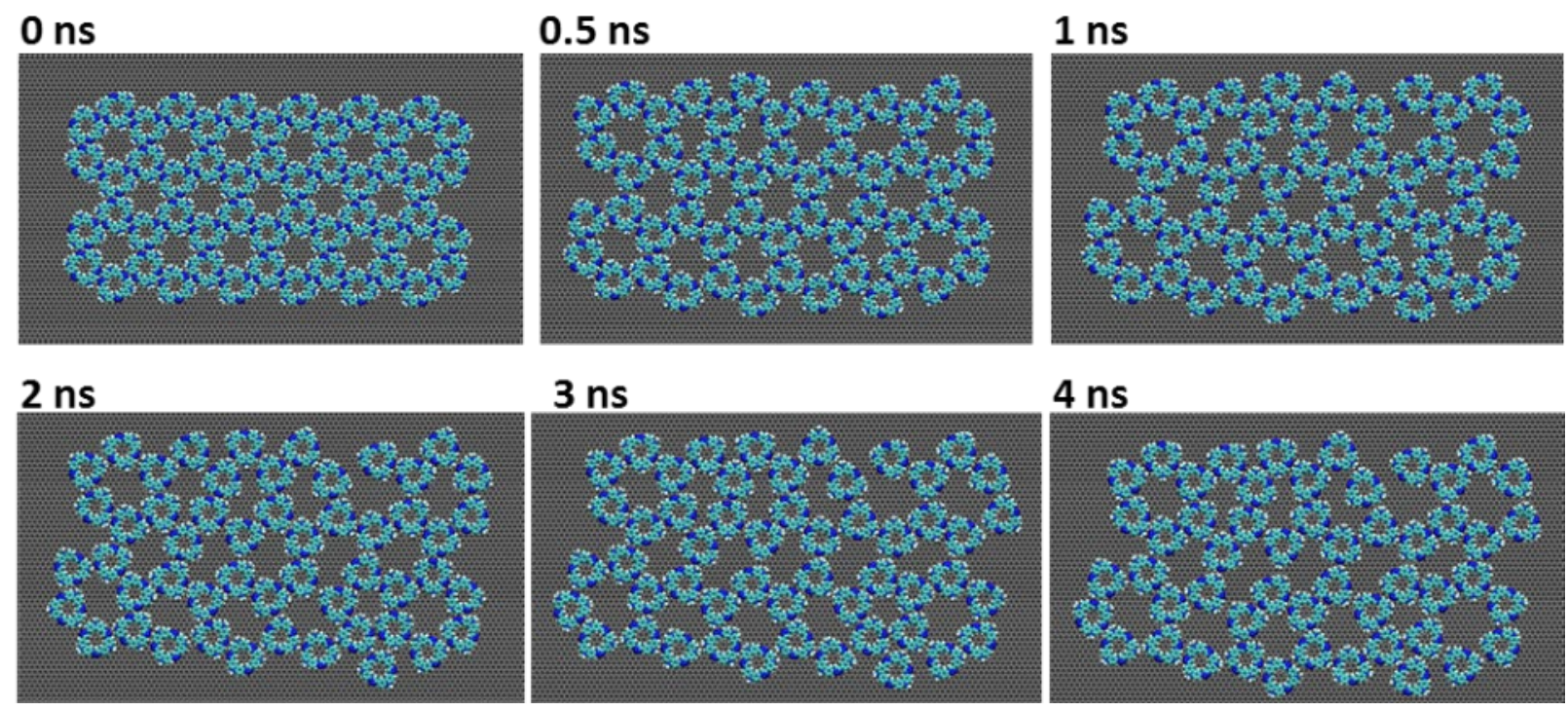

Figure S19. MD simulation of tricarb-1-1-1 in TCB. Loss of honeycomb for tricarb-1-1-1 starts from both the center and edges of the domain. Solvent molecules are omitted from the figure for clarity. 

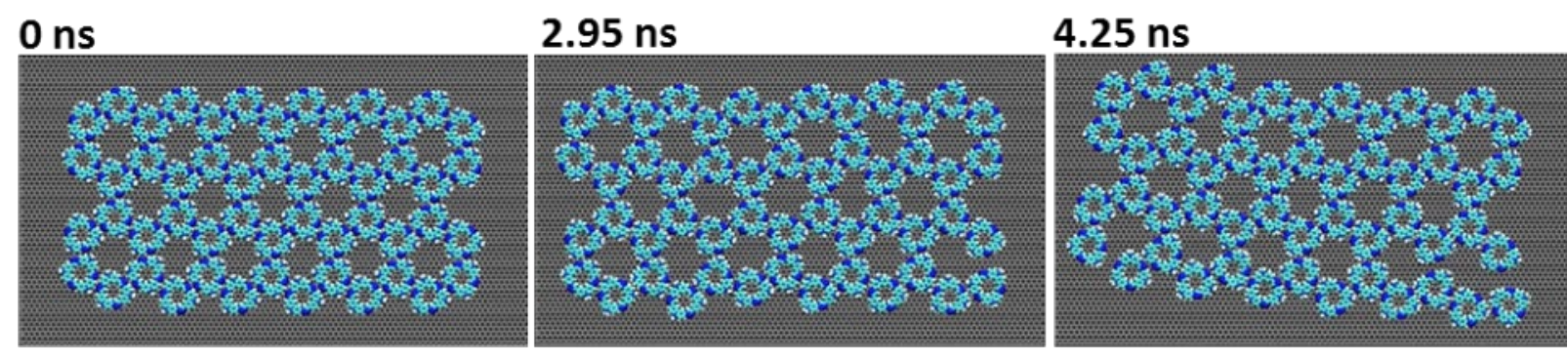

\subsection{5 ns}
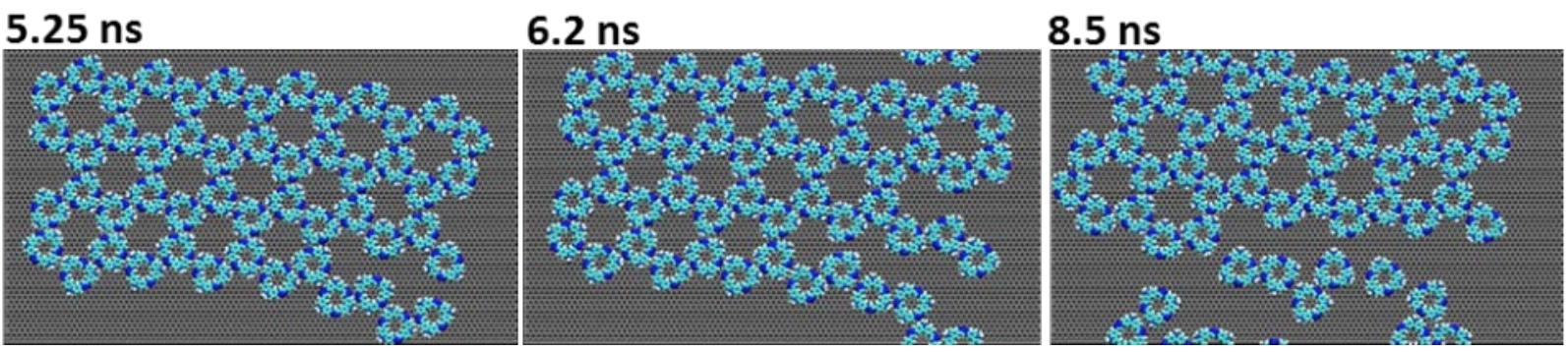

Figure S20. MD simulation of tricarb-1-1-1 in toluene. Loss of honeycomb for tricarb-1-1-1 starts from the edge molecules and propagate to the middle of the honeycomb island. Loss of honeycomb structure occurs at a slower timescale in toluene than TCB. Solvent molecules are omitted from the figure for clarity. 


\section{S13. Self-assembly of other tricarb species}

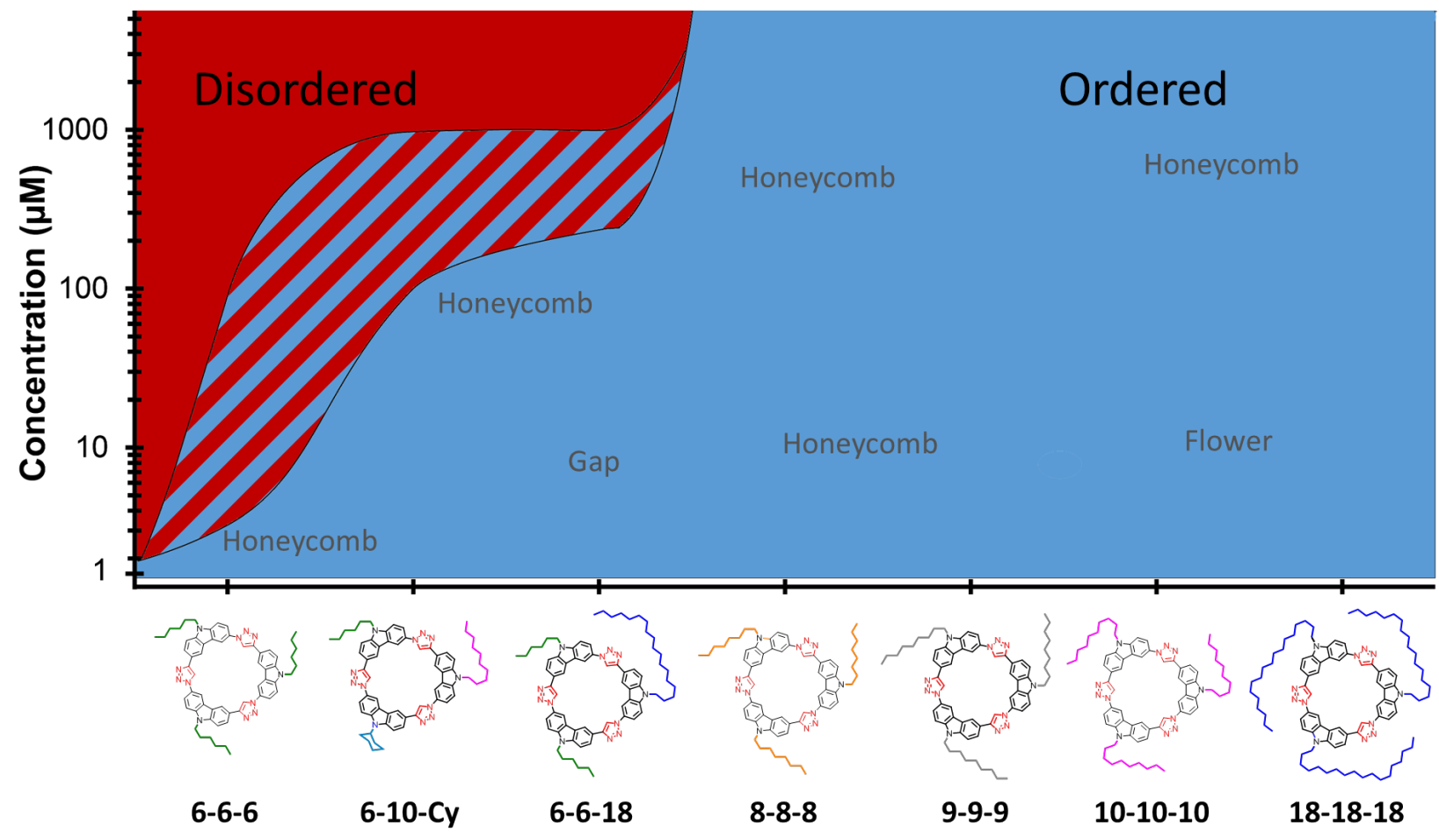

Figure S21. Tricarb self-assembly structure as a function of concentration and peripheral functionalization (solvent: TCB, temperature: $20^{\circ} \mathrm{C}$ ). Striped area represents concentrations where disordered and honeycomb co-exist. Refer to reference 1 of the SI for STM images, unit cells, and models of the various structures and tricarb species. 


\section{S14. Ordered domain size as a function of solvent, temperature, and peripheral groups}

Honeycomb domain sizes are tabulated in Table S6. Here, we add a few other notes about domain size observations to supplement the results reported in the main text.

Domain size effects are also observed in experiments where we observe other packing structures. For example, at $0.5 \mu \mathrm{M}$, tricarb-10-10-10 forms large ordered domains of the flower structure, in which a single domain regularly spans over a $40,000 \mathrm{~nm}^{2}$ area. Those domains are much larger than the honeycomb domains for the same molecule at higher concentration (Table S6).

At concentrations below the onset of disordered assembly, there is no qualitative difference in honeycomb domain size across tricarb species/peripheral groups (Table S6), as noted in the main text. At $1 \mu \mathrm{M}$, both tricarb-6-6-6 and tricarb-6-10-Cy form large honeycomb domains that span over $10,000 \mathrm{~nm}^{2}$. At higher concentrations in which disordered structures are observed, smaller tricarb species form smaller ordered domains compared to larger tricarb species at the same concentration (Table S6). For example, tricarb-6-10-Cy at $10 \mu \mathrm{M}$, a 10,000 $\mathrm{nm}^{2}$ area contains one honeycomb domain spanning over $10,000 \mathrm{~nm}^{2}$. For tricarb-6-6-6 at $10 \mu \mathrm{M}$, disordered structures co-exist with honeycomb, and the coverage of honeycomb and disordered domains varies throughout the surface. In a $10,000 \mathrm{~nm}^{2}$ area, a single honeycomb a domain may span an area of roughly $8,000 \mathrm{~nm}^{2}$ with $2,000 \mathrm{~nm}^{2}$ of disordered structures. Alternatively, a different $10,000 \mathrm{~nm}^{2}$ area of tricarb-6-6-6 at $10 \mu \mathrm{M}$ may contain mostly disordered structures with a small honeycomb domain spanning only $2,500 \mathrm{~nm}^{2}$. We note that a direct comparison of honeycomb domain size across tricarb species at some concentrations is not possible simply because other polymorphs (e.g., gap and flower) assemble (see footnotes to Table S6).

Table S6. Range of honeycomb (HC) domain sizes for different concentrations and tricarb species.

\begin{tabular}{|c|c|c|c|c|c|}
\hline & \multicolumn{4}{|c|}{ Honeycomb domain size $\left(\mathrm{nm}^{2}\right)$} \\
\hline & & Tricarb-6-6-6 & Tricarb-6-10-Cy & Tricarb-6-6-18 & Tricarb-10-10-10 \\
\hline \multirow{4}{*}{ 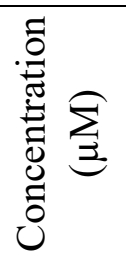 } & 1 & $>10,000^{\mathrm{a}}$ & $>10,000^{\mathrm{a}}$ & $(\text { no } H C)^{b}$ & $(\text { no } H C)^{b}$ \\
\hline & 10 & 2,500 to 8,000 & $>10,000^{\mathrm{a}}$ & $(\text { no } H C)^{b}$ & $(\text { no } H C)^{b}$ \\
\hline & 100 & (no HC) & 600 to 10,000 & 900 to $3,000^{\mathrm{c}}$ & 600 to $>10,000^{\mathrm{a}, \mathrm{d}}$ \\
\hline & 3000 & $-{ }^{\mathrm{e}}$ & $-{ }^{\mathrm{e}}$ & $-{ }^{\mathrm{e}}$ & 30 to 6,500 \\
\hline
\end{tabular}

${ }^{a}$ Domains spans an area larger than the $10,000 \mathrm{~nm}^{2}$ scan size.

${ }^{b}$ At 1-10 $\mu \mathrm{M}$, tricarb-6-6-18 and tricarb-10-10-10 do not assemble into honeycomb, but assemble into gap and flower, respectively.

${ }^{\mathrm{c}}$ At $100 \mu \mathrm{M}$ for tricarb-6-6-18, both gap and honeycomb co-exist. This value represents domain size of honeycomb only.

${ }^{\mathrm{d}}$ At $100 \mu \mathrm{M}$ for tricarb-10-10-10, there is an evolution from flower to honeycomb over the course of tens of minutes. Honeycomb domains grow over time.

${ }^{\mathrm{e}}$ Due to poor solubility, a $3000 \mu \mathrm{M}$ solution in TCB is not possible. 


\section{S15. References}

1. Dobscha, J. R.; Castillo, H. D.; Li, Y.; Fadler, R. E.; Taylor, R. D.; Brown, A. A.; Trainor, Q. C.; Tait, S. L.; Flood, A. H. Sequence-Defined Macrocycles for Understanding and Controlling the Build-Up of Hierarchical Order in Self-Assembled 2D Arrays. J. Am. Chem. Soc. 2019, 141, 17588-17600.

2. MacKerell, A. D.; Bashford, D.; Bellott, M.; Dunbrack, R. L.; Evanseck, J. D.; Field, M. J.; Fischer, S.; Gao, J.; Guo, H.; Ha, S.; Joseph-McCarthy, D.; Kuchnir, L.; Kuczera, K.; Lau, F. T. K.; Mattos, C.; Michnick, S.; Ngo, T.; Nguyen, D. T.; Prodhom, B.; Reiher, W. E.; Roux, B.; Schlenkrich, M.; Smith, J. C.; Stote, R.; Straub, J.; Watanabe, M.; Wiórkiewicz-Kuczera, J.; Yin, D.; Karplus, M. All-Atom Empirical Potential for Molecular Modeling and Dynamics Studies of Proteins. J. Phys. Chem. B 1998, 102, 3586-3616.

3. Debnath, S.; Yang, J.; Ortoleva, P.; Raghavachari, K. Understanding the Origin of 2D Self-Assembly of Tricarbazole Macrocycles: An Integrated Quantum Mechanical/Molecular Dynamics Study. J. Phys. Chem. C 2019, 123, 17616-17623.

4. Lee, S.; Hirsch, B. E.; Liu, Y.; Dobscha, J. R.; Burke, D. W.; Tait, S. L.; Flood, A. H. Multifunctional Tricarbazolo Triazolophane Macrocycles: One-Pot Preparation, Anion Binding, and Hierarchical Self-Organization of Multilayers. Chem. Eur. J. 2016, 22, 560569. 